\title{
Recurrent dislocation is different from habitual dislocation of patella
}

\author{
Sumit Batra
}

Received: 24 June 2014 / Accepted: 15 July 2014 /Published online: 31 July 2014

(C) SICOT aisbl 2014

\section{Dear Sir,}

I read the article by Ji et al. [1] wherein they have described the technique of medial patella retinaculum plasty for treatment of habitual dislocation of patella in adolescents.

The author has wrongly used the term "habitual dislocation" in various sections of the article including the title. The author has also used the term "recurrent dislocation" at a few places in the article, especially in the Material and Methods section, which is the correct term for the type of cases that he has described in the article.

The difference between habitual dislocation and recurrent dislocation has been clearly defined in the literature and these two terms are not interchangeable [2-5]. Habitual dislocation is a condition wherein the patella dislocates each time the knee is flexed. On the other hand, recurrent dislocation is a condition wherein the condition is episodic and usually triggered by a traumatic event.

The author confuses the readers as the presentation, pathology and management is different for these two conditions and the message received at the end of the article relates to recurrent dislocation only, whereas the author has used the term habitual dislocation wrongly in the title, abstract, introduction and results.

\section{References}

1. Ji G, Wang F, Zhang Y, Chen B, Ma L, Deng J (2012) Medial patella retinaculum plasty for treatment of habitual dislocation in adolescents. Int Orthop 36:1819-1825

2. Baskhi DP (1981) Restoration of dynamic stability of the patella by pes anserinus transposition. A new approach. J Bone Joint Surg (Br) 63-B:399-403

3. Bergman N, Williams P (1988) Habitual dislocation of the patella in flexion. J Bone Joint Surg (Br) 70-B:415-419

4. Benoit B et al (2007) Long term outcome of surgically treated habitual patella dislocation in children with coexistant patella alta. A minimum follow- up of 11 years. J Bone Joint Surg(Br) 89-B:1172-1177

5. Joo SY et al (2007) The four in one procedure for habitual dislocation of patella in children. J Bone Joint Surg (Br) 89-B:1645-1649

\footnotetext{
S. Batra $(\bowtie)$

Trauma and Orthopaedics, The Great Western Hospital, Swindon,

UK

e-mail: sumitbatra104@hotmail.com
} 